\title{
28 Resarch Soure \\ The small-size laser shock clinch-bonded hybrid joining of Al foils
}

Yiqun Wang

Guoxin Lu

Zhong Ji ( $\sim$ jizhong@sdu.edu.cn )

Shandong University

Ren Liu

Chao Zheng

\section{Research Article}

Keywords: Laser shock forming, Clinch-bonded hybrid joining, FEM simulation, Failure analysis

Posted Date: March 2nd, 2022

DOI: https://doi.org/10.21203/rs.3.rs-1388076/v1

License: (c) (i) This work is licensed under a Creative Commons Attribution 4.0 International License.

Read Full License 


\section{Abstract}

In this paper, an original process that making small-sized clinch-bonded hybrid joints by laser shock forming is put forward and developed, two metal foils, one adhesive layer and one perforated stainless steel sheet are joined together under continuous laser shocks. Finite element models are established to simulate the forming process and the shearing behavior of the hybrid joints. The effect of the adhesive on the manufacturing process is emphatically discussed. The shearing and peeling tests of the hybrid joints are compared with that of single clinched and pure bonded joints. The failure mode of the hybrid joint under loading is analyzed along with numerical simulation taking a shearing test for instance. The experimental results show that the cured adhesive with thin thickness is beneficial to the subsequent clinching process; the application of adhesive can greatly improve the mechanical strength of the single mechanical clinched joints; the failure process of the hybrid joints is that the adhesive fails first and then the interlock. The laser shock forming has enabled the precision manufacturing of small-sized clinchbonded hybrid joints, which can play a significant role in electronic component processing and other special working conditions.

\section{Introduction}

Since the requirements of modern industry are becoming multiple and complex, single joining methods are gradually getting unable to be applied in all the processing situation, researchers started to seek ways of combining different joining methods, among which the combination of mechanical clinching and adhesive bonding is getting more and more attention.

Early in 1989, Wines tried to use clinching in adhesive assembly operations [1]. He first dispensed a layer of adhesive between two sheets, then performed the mechanical clinching process before the adhesive cured completely. The strength test results had shown that combining clinching and bonding could have a great enhancement on the joint strength, which are comparable to or even exceed that of the spot welded joints.

The basic purpose of clinch-bonded hybrid joining is to add adhesive in clinching joints and thus can promote such as joint mechanical strength, corrosion resistance, etc. Over the decades, plenty of achievements have been made by scientists around the world. Sadowski et al. [2-4] described the basic technological process of creating clinch-bonded joints in detail, along with studies on joint strength, durability, and failure types. The mechanical properties of adhesive and clinching process are crucial to the hybrid joint production, brittle and stiff adhesive could not sustain plastic deformation and microdamage shall occur on its interface during clinching identation. The adhesive layer of hybrid joints tend to fail first in tensile tests, then follows the interlock structure. To analyze the hybrid joints behavior, the cohesive-zone (CZ) model was used to simulate the damage process of the adhesive layer, while the Gurson-Tvergaard-Needleman (GTN) damage model and the Ductile Damage Model (DDM) were respectively applied for metallic material damage. He et al. [5] compared the mechanical strength and failure between clinched and clinch-bonded joints of 7075 aluminum alloy through shearing tests and 
finite element method (FEM) simulation. The upper sheet was subjected to high stress than the lower sheet and the maximum stress occurs at the neck of upper sheet, the failure mode of the clinch-bonded hybrid joints was also neck fracture mode. Lei et al. [6] explored the performance variation of hybrid joints with different material combinations, the failure surface of adhesive was observed using a scanning electronic microscope (SEM), the shearing and peeling strength are mainly provided by adhesive and undercut structure respectively. During the hybrid joint manufacturing progress, layer-gummed adhesive tends to redistribute and gather into adhesive pockets. This time-dependent formation process of adhesive was followed up and analyzed by Fricke et al. [7] through FEM. Gerstmann and Awiszus [8] further conducted a FEM analysis of the clinch-bonded hybrid joining process, using a rate-power-law equation to simulate the bonding and tearing behaviors of adhesive. Small adhesive layer thickness and high blank holder force are recommended, and enough intermediate stop of punch should be adopted for minimizing adhesive pocket and maximizing the interlock.

The laser shock forming (LSF) technology has been attracting people's attention since the 1960s, the high-pressure shock wave induced by laser made this technique possible to be applied in material processing, while the idea of laser shock clinching was originally presented by Ji et al. in $2008[9,10]$, which especially fits the clinching of thin metal foils. When the short-pulse laser irradiated to the energy absorbent, the induced shock wave by generated plasma mass can play a role as flexible punch and with the restraint of confinement layer and rigidity die, forcing sheets flowing into the cavity, thus form the interlock structure and finish clinching. Wielage and Vollertsen [11] realized such process of manufacturing clinched joints through laser methods under experimental condition. The laser shock clinching of aluminum foil to perforated glass sheet and plastic sheet were later achieved by these researchers, which expanded the application of this process $[12,13]$.

Aiming at laser shock clinching process, Wang et al. designed two sets of mold systems, one can achieve the simultaneous clinching and cutting of metal foils by laser shock forming, piercing of lower foil and forming of upper foil are performed in one step; the other one can clinch two foils without punching holes, only cutting through paralleled lines on two foils $[14,15]$.

In the Ji group, Wang et al. [16] studied the shearing and peeling strength as well as fracture process of laser-clinched joints through experiments and FEM analysis, process windows between different factors were also established. By clinching two layers of similar or dissimilar materials to a perforated sheet, the double-layer clinching of copper and aluminum foils to steel sheet was also accomplished using the laser shocking technique [17]. You et al. [18] creatively made line undercut of copper foils by incremental laser shocks, proving the suitability of laser manufacturing irregular-shaped joint. Wang et al. (2021) further developed the investigation on linear undercut, achieved making two-layer round end rectangular joint by laser shock. Zheng et al. (2020) explored the material behavior in $\mathrm{Cu} / \mathrm{Fe}$ laser clinching through experiments and FEM analysis, the influence of laser density and shock wave propagation on foil thickness variation and undercut forming was specially studied. 
Though there are numerous results on both clinch-bonded hybrid joining in which mechanical punch is used, and laser shock clinching in which pulsed laser beam is used, no research has been published to have the two techniques assembled. The behaviors of adhesive under laser shocking loads are not clear, and the co-interaction between metal foils and adhesive remains to be explored. By laser shocking technique, the size of clinch-bonded hybrid joints can be made smaller, and with its advantages in sealing and corrosion resistance, this process can have great significance and long-range prospects in electronic component manufacturing.

In this paper, a three-layer structure consists of two metal foils and one adhesive layer is clinched to a perforated steel sheet through LSF, on the basic of laser shock metal foil clinching. FEM simulations of forming a hybrid joint and its shearing fracture progress are established by LS-DYNA. The forming process of the hybrid joint is analyzed stage by stage along with the FEM results. Hybrid joints of different adhesive states and layer thickness are manufactured to explore the influence of adhesive in joint forming. Shearing and peeling tests are carried out for contrasting the joint strength of hybrid, singleclinched, and single-bonded joints. The shearing-failed mode of hybrid joints is analyzed along with experimental and simulation results.

\section{Experiments}

\subsection{Experimental mechanism}

The schematic of laser shock clinch-bonded hybrid joining and its device is as shown in Fig. 1. An adhesive layer is gummed between two foils in advance, curing or not before laser shock clinching can be selected. The confinement layer coated with energy absorbent is supposed to have no energy loss during laser irradiating. When the short-pulse laser beam acts on the absorbent, the absorbent will absorb the laser energy and generate plasma vapor with high pressure, which can play the role of shock wave and be applied in material processing. With the constraint of the confinement layer and blank holder, the shock wave may serve as a flexible punch, forcing materials flowing into the perforated hole on steel sheet, then extending in radial direction and finally form an undercut structure, thus accomplish the hybrid joining process which includes adhesive bonding and mechanical clinching.

\subsection{Specimen preparation}

The laser generator used here is an Nd:YAG short-pulse laser (Nimma-600, 650mJ/1064nm/ 10Hz/700V), the diameter of the laser spot is adjusted to be $5 \mathrm{~mm}$; a $3 \mathrm{~mm}$-thick $\mathrm{K} 9$ glass sheet is applied as a confinement layer; the absorbent is carbon black, extracted from prepared Chinese ink.

The metal foils are annealed 1060 aluminum foils with thickness of $30 \mu \mathrm{m}$. The material of the perforated steel sheet is 304 stainless steel, pre-pierced by laser cutting. The adhesive used in this paper is Henkel Teroson EP 5055 structural adhesive, which shall cure completely in 48 hours at room temperature after gumming, or in 0.5 hours at a temperature higher than $80^{\circ} \mathrm{C}$. 
Lap and T-specimens of clinch-bonded hybrid joints, single clinched joints, and single bonded joints are manufactured to contrast their shearing and peeling strength, each kind of joints have been made 5 specimens. Schematic and dimensions of lap joints, T-joints, and mold system, are respectively as shown in Table 1 and Fig. 2. Al-Al hybrid and clinched joints are manufactured by $320 \mathrm{~mJ}$ laser pulses. Bonded joints are made without perforated sheets. To cure adhesive and release residual stress completely, each specimen is tested or observed 48 hours after manufacturing.

Table 1

Dimension of lap joint and mold system.

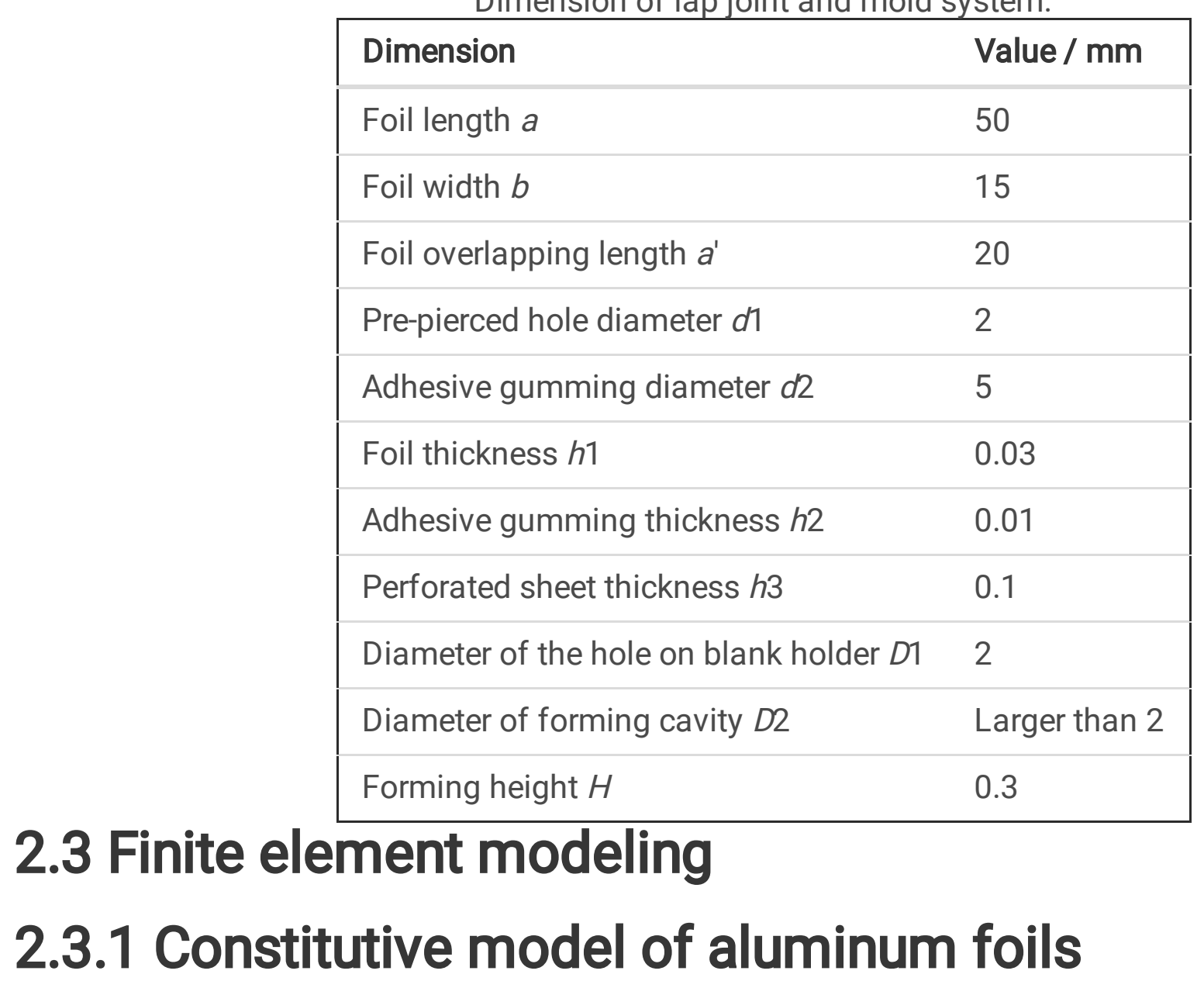

For simulating the stress-strain relationship of aluminum foils, the Johnson-Cook (J-C) constitutive model is applied, which is widely adopted in material processing with high strain rate such as laser shock forming, its equation is shown as follows:

$$
\sigma_{\mathrm{y}}=\left(\mathrm{A}+\mathrm{B} \varepsilon^{\mathrm{n}}\right)\left(1+\mathrm{Cln} \frac{\dot{\varepsilon}}{\varepsilon_{0}}\right)\left[1-\left(\frac{\mathrm{T}-\mathrm{T}_{\mathrm{r}}}{\mathrm{T}_{\mathrm{m}}-\mathrm{T}_{\mathrm{r}}}\right)^{\mathrm{m}}\right]
$$


where $\sigma_{y}$ is the dynamic yield strength of the foils; $A, B, C, n$, and $\mathrm{m}$ are input constants; $\varepsilon$ is the the effective plastic strain; $\dot{\varepsilon}$ and $\varepsilon_{0}$ are the effective strain rate and the reference effective strain rate; $T, T_{n}$ and $T_{m}$ are the environment temperature during processing, the room temperature, the material melting temperature. The value of the constants for aluminum is as shown in Table 2 [21].

Table 2

Value of the constants in the J-C constitutive model of aluminum [21].

\begin{tabular}{|c|c|c|c|c|c|c|}
\hline$A(\mathrm{MPa})$ & $B(\mathrm{MPa})$ & $c$ & $n$ & $m$ & $T_{r}$ & $T_{m}$ \\
\hline 148.4 & 345.50000 & 0.0010000 & 0.1830000 & 0.8950000 & 293 & 916 \\
\hline
\end{tabular}

For simulating the manufacturing process of the hybrid joint, the flowing and bonding of adhesive are defined in two ways: a piecewise linear plasticity constitutive model for adhesive flowing, and a specific contact condition describing the sticking and peeling behavior of the interface consists of adhesive and foils. For the constitutive model of adhesive, only the basic mechanical parameters and stress-strain relationships are defined, the bonding force is not included. According to its technical data sheet, the cured adhesive is hard but not brittle, and the basic mechanical properties are as shown in Table 3 [22]. The stress-strain relationship derived from a tensile test of casted adhesive specimen is as shown in Fig. 3. For the contact definition, during the whole forming process, the adhesive and metal foils are tied together until the external normal or tangential loads reaching preset values, which are equivalent to the adhesive bonding strength, and after that such tied relationship will be immediately deleted.

Table 3

Mechanical properties of cured Henkel Teroson EP 5055 adhesive [22].

\begin{tabular}{|lll|}
\hline Density (g/ml) & Young's modulus (MPa) & Shear strength (MPa) \\
\hline 1.05 & 1500 & 20 \\
\hline
\end{tabular}

In the simulation of the shearing-failure process of the hybrid joint, the material model of the adhesive has been simplified that no geometrical model of adhesive exists but only a contact condition defining the bonding behavior between two foils, since the adhesive layer thickness is much thinner compared to the foil thickness and the whole button size. The contact definition is the same as mentioned below, except the applied interface is between the two foils.

\section{Results And Discussion \\ 3.1 Quality evaluation}

Figure 4 shows the section view and surface morphology of an aluminum-adhesive-aluminum-stainless steel (Al/Ad/Al/Ss) hybrid joint, the diameter of which is $2 \mathrm{~mm}$; a $10-\mu \mathrm{m}$ thick adhesive layer is gummed 
and completely cured before laser shocking; the whole structure is formed by 60 times laser shocking at an energy of $320 \mathrm{~mJ}$. In Fig. 4 (a), the three layers are successfully clinched into the pre-pierced hole on the steel sheet, foil thickness in the button has reduced obviously, especially at the corner of the undercut. Besides, comparing to its flat shape before clinching, adhesive has redistributed to pockets at button corner and center, tracking such behavior of adhesive is of much importance to the manufacturing of hybrid joints. Interlock depths in this paper are defined as the horizontal distance of the part which vertically overlaps between upper and lower foils or lower foil and perforated sheet, as marked in Fig. 4 (a). The interlock depth between upper and lower foils tend to be shorter than between lower foil and perforated sheet, since the existence of redistributed adhesive pocket has occupied a certain flowing space of upper foil, the larger the adhesive pocket is, the more obvious the size difference between two kinds of interlocks will be. Figure 4 (b) shows the morphology of the front surface of the joint, the rolling stripe of the foil surface inside the button area has disappeared due to the laser ablation, while that outside the button is still clear. Figure 4 (c) exhibits the feature view of adhesive in the marked area in (a), the uneven upper surface is resulted by the laser ablation. The irregular mass between the foils is the redistributed adhesive, which has shown good saturation and does not get peeled from Al foils during the forming process.

Figure 5 presents the three-layer thickness distribution curves of the hybrid joint in Fig. 4 (a), the measurement positions of which are as signed. As for the upper and lower foils, the most serious thickness reduction concentrates at the area (position 12-15, 35-38) close to the bottom corner, foil thickness at die cutting edge (position 3-6, 47-49), and sidewall (position 8,44,45) also reduced but were not that serious. Comparing to the initial Al foil thickness which is $30 \mu \mathrm{m}$, foils in the very center of the clinch button (position 23-25) have nearly no thickness reduction. Besides, due to the material flowing behavior under external loads, foils outside the clinch button (position 1-3, 50-52) appear to be thicker than their initial thickness. Adhesive pocket mainly generated at clinch button corner (position 10,11,4143) and center (position 20-26), as pointed out in Fig. 4 (a), the size of which is much larger than its initial thickness; adhesive at sidewall (position 6-8, 45-48) owns the thinnest thickness.

\subsection{Manufacturing process}

Figure 6 contrasts the hybrid joint section views at different forming stages in the experiment and numerical simulation, laser energy is $320 \mathrm{~mJ}$, the shocking number from (a) to (f) are respectively 10,20 , ..., 60, unit of effective stress is MPa. As can be observed in both two results, during the whole clinching process, the deformation rate of materials has gradually decreased since the reduction of radial component loads which act on button sidewall and force the foils extending. The effective stress distribution of each forming stage is also illustrated, for metal foils, in general, the local stress progressively increases from out of button to the center and did not seem to be significantly affected by material bending. Effective stress change of the same part at different stages is not conspicuous during the whole process. Comparing with Al foils, the overall stress level of adhesive is much lower, this is most possibly caused by its conspicuously weaker mechanical strength. Since the adhesive layer is very thin and ductile, the existence of adhesive does not seem to have a noticeable effect on foil forming, whether 
facilitation or resistance. In addition, the shape of the adhesive layer or pocket is strongly restricted by the foil shape.

\subsection{Adhesive state and layer thickness}

Figure 7 exhibits the section views of Al-Al hybrid joints with different adhesive layer thickness, the three joints are all manufactured by $320 \mathrm{~mJ}$ laser shocks and shocking numbers are 60,60 , and 100, the joint in (c) takes more pulses to form undercut. Two foils are simply clinched to a perforated sheet without gumming in Fig. 7 (a) while an adhesive layer of $5 \mu \mathrm{m}$ thickness is applied in Fig. 7 (b). The general shape of hybrid joints with an adhesive thickness of 0,5 as well as $10 \mu \mathrm{m}$ are approximately the same, which shows that the thin adhesive layer may have little or even negligible effects on joint forming. However, in Fig. 7 (c), the thickness of the adhesive layer is $20 \mu \mathrm{m}$, the excessive adhesive gathers at the button bottom, results in locally non-uniformity of mechanical property and forms an uneven structure under laser shocking. As has been discussed below, the most severe thickness reduction of Al foils appeared between the clinch button corner and center, which is marked in Fig. 7 (c). Foils of this part fracture under the double function of adhesive bulging and thickness reduction, plenty of adhesives have leaked out of the joint.

Through the observation of hybrid joints with different adhesive layer thickness, it is reasonable to conclude that the existence of adhesive may have a slight influence on the clinching process of hybrid joints, only when its thickness remains a rather thin level, while excess adhesive can easily lead to structural instability and material fracture. For hybrid joints made of thin metal foils, gumming adhesive layer as thin as possible is beneficial for joint forming, not only improving joint quality but also reducing processing time.

Figure 8 shows the section view of a hybrid joint in which the adhesive layer remained uncured before clinching, the thickness distribution of its adhesive layer is compared with cured adhesive in Fig. 9, the measurement positions are as shown in Fig. 4 (a) and Fig. 8. Seeing from the curves, thickness fluctuation of uncured-formed adhesive is milder and has manifested better thickness uniformity, this may be caused by the fact that uncured adhesive is more likely to flow during laser shocking, while cured adhesive tends more to get compressed. However, the shape of the hybrid joint formed with uncured adhesive may not be so well as the cured-formed hybrid joint, flexible adhesive is likely to lead to structural instability.

\subsection{Joint strength}

Figure 10 and Fig. 11 illustrate the shearing and peeling test results of Al-Al joints, where (a) is the forcedisplacement curves and (b) is the maximum force and energy absorption contrast derived from curves in (a).

For the one-step made Al-Al joints, both clinched and bonded joints have shown weaker shearing strength than hybrid joints, not only affordable shearing force but also ultimate displacement and energy absorption ability, as shown in Fig. 10 (a) and (b). This means adding adhesive in clinching can 
immensely promote the shearing strength of joints. However, it should be noticed that the instability of hybrid joining quality is also more severe. The uncertainty of maximum shearing force and energy absorption are specifically described in Fig. 10 (b) using error bars, the two properties of hybrid joining all exhibited higher value fluctuation comparing to the other two kinds of joints.

When it comes to peeling strength, Al-Al hybrid joints also showed better performance than the other joints, as Fig. 11 presented. Hybrid and bonded joints had a longer failing distance than clinched joints, this is obviously due to the larger the adhesive gumming area comparing to the clinching button. The shape of the force-displacement curve of hybrid joint expresses an apparent tendency of accumulating clinched and bonded joint curves; the peeling strength of the bonded joint is not so well as it performed in shearing test, however, combining adhesive with clinching can greatly promote joint affordable peeling loads and energy-absorbing ability.

\subsection{Fracture analysis}

The fracture analysis of clinch-bonded hybrid joint is carried out taking an Al-Al shearing-failed joint for instance. Figure 12 is the digital microscope observation of the failed joint, (a) and (b) show the innerside joint surface of upper and lower foils, (c) and (d) are the failed button structure on both foils, tensile directions are assigned in the picture. In Fig. 12 (a) and (b), failed adhesive layer can easily be recognized. The residual adhesive on both foil surface are not continuous, speckles can be seen in the adhesive area since adhesive gummed before manufacturing is a whole piece without blank, this phenomenon means adhesive has a certain degree of volume shrinkage during curing. What's more, there are residual adhesive on both the two surface and their area are almost the same as circled out in Fig. 12 (a) and (b), which proves that the failure mode of adhesive is its interior structure rupturing rather than peeling at the interface between adhesive and foil, the bonding force between adhesive and foil was larger than that inside the adhesive itself. As exhibited in Fig. 12 (c), the button interlock structure is conspicuously deformed under external loads, however, on account of the protection of the perforated steel sheet, the interlock structure of the lower foil in Fig. 12 (d) is still in good condition.

The shearing force-displacement curves derived from test results and numerical simulation are contrasted together in Fig. 13 (a). The simulation result has generally shown uniformity to some extent with the true experimental situation. In the very beginning of shearing process, there is a yield-like phenomenon in simulation results between stage 1 and 2, where the curve fluctuates vertically and gradually reduced as displacement increasing. Such fluctuation is probably caused by the bonding failure between upper and lower foil elements within a short time, since it is not observed in the test result. To explore the failure mode of the hybrid joint, features of the joint at five different failure steps as well as the corresponding simulated joint section views are presented in Fig. 13 (b) and Fig. 14. As displacement increasing, in the period from stage 1 to 2 , adhesive inside the button gradually failed; from stage 2 to 3 , adhesive at interlock and outside the button all failed subsequently, the upper foil has apparent curling up; from stage 3 to 4 , the two foils start to separate at the side which is opposite to the tensile direction since interlock of this part fails first; the interlock failure expanded as shearing test coming to stage 4 and 
5 and finished at stage 5 , then accomplished the shearing failure of the hybrid joint. In general, the failure mode of the hybrid joint is adhesive fails first then follows the interlock.

\section{Conclusion}

In this paper, 1060 aluminum foil, 304 perforated stainless steel sheet, and Henkel Teroson EP 5055 structural adhesive, are employed in the laser shock clinch-bonded hybrid joining. The adhesive layer of different thicknesses and curing states are studied to explore their influence on joint manufacturing. Three kinds of joint, single clinched, pure bonded and hybrid, are all applied in the uniaxial tensile shearing and peeling test for strength comparison. The failure mode of the hybrid joint is also researched. A FEM simulation is conducted to assist in analyzing forming process and joint failure. The results can be concluded that:

(a) In the laser shock clinch-bonded hybrid joining of thin metal foils, the most serious thickness reduction of foils appeard at the area close to the button corner. During the laser shocking, the deformation rate of materials gradually decreases;

(b) The thin adhesive layer has little influence on the joint forming, while the thick adhesive layer can easily lead to foil fracture. Cured adhesive is better for hybrid joint processing than uncured adhesive;

(c) Applying adhesive in clinching can have a great promotion in joint shearing and peeling strength. The general shearing failure mode of clinch-bonded hybrid joints is that, the adhesive fails first, then follows the interlock structure.

\section{Declarations}

\section{Funding}

This work is supported by the National Natural Science Foundation of China (Nos. 52075298, 51575314, 51801031,52075299 ) and the Fund of the State Key Laboratory of Solidification Processing in NPU (No. SKLSP202014).

\section{Conflicts of interest/Competing interests}

The authors have no relevant financial or non-financial interests to disclose.

\section{Availability of data and material}

All data generated or analysed during this study are included in this published article.

\section{Code availability}

Not applicable. 


\section{Ethics approval}

Not applicable.

\section{Consent to participate}

The authors declare that they consent to participate in this paper.

\section{Consent for publication}

This manuscript is approved by all authors for publication.

\section{Authors' contributions}

All authors contributed to the study conception and design. Material preparation, data collection and analysis were performed by [Yiqun Wang]. The first draft of the manuscript was written by [Yiqun Wang] and all authors commented on previous versions of the manuscript. All authors read and approved the final manuscript.

\section{References}

1. Wines BL (1989) Adhesive and mechanical clinch bond strengths - A comparison to spot weld strengths. SAE Tech Paper 890517. https://doi.org/10.4271/890517

2. Sadowski T, Balawender T (2010) Technology of clinch-adhesive joints. In: da Silva, L., Pirondi, A., Öchsner, A. (Eds.), Hybrid Adhesive Joints. Advanced Structured Materials, vol 6. Springer, Berlin, Heidelberg, pp. 149-176

3. Balawender T, Sadowski T, Kneć M (2011) Technological problems and experimental investigation of hybrid: Clinched - adhesively bonded joint. C Arch Metall Mater 56(2):439-446

4. Sadowski T, Balawender T, Golewski P (2015) Technological aspects of manufacturing and numerical modelling of clinch-adhesive joints. Technological Aspects of Manufacturing and Numerical Modelling of Clinch-Adhesive Joints. SpringerBriefs in Applied Sciences and Technology. Computational Mechanics), Springer, Cham, pp 1-59

5. He X, Zhao L, Yang H et al (2014) Investigations of strength and energy absorption of clinched joints. Comput Mater Sci 94:58-65

6. Lei L, He X, Zhao D et al (2018) Clinch-bonded hybrid joining for similar and dissimilar copper alloy, aluminium alloy and galvanised steel sheets. Thin Wall Struct 131:393-403

7. Fricke H, Vallée $T$ (2015) Numerical modeling of hybrid-bonded joints. J Adhes 92(7-9):652-664

8. Gerstmann T, Awiszus B (2020) Hybrid joining: Numerical process development of flat-clinchbonding.J. Mater. Process. Technol.277

9. Bell CE, Landt JA (1967) Laser-induced high-pressure shock waves in water. Appl Phys Lett 10(2):46-48 
10. Ji Z, Liu R, Wang D et al (2008) A micro clinching method and its device for joining ultra-thin sheets with pulsed laser.Chinese Patent.ZL200810014018.1.

11. Wielage H, Vollertsen F (2011) Undercuts by laser shock forming. AIP Conference Proceedings. 1353, 1309-1312, https://doi.org/10.1063/1.3589697

12. Veenaas S, Vollertsen F (2018) Mechanical joining of glass and aluminium. Key Eng Mater 767:369376

13. Veenaas S, Vollertsen F, Czotscher T (2019) Joining by laser induced shock waves of aluminum and plastics. AIP Conference Proceedings. 2113, 050029, https://doi.org/10.1063/1.5112593

14. Wang X, Li C, Ma Y et al (2016) An experimental study on micro clinching of metal foils with cutting by laser shock forming. Mater (Basel) 9:571

15. Li X, Wang X, Shen Z et al (2019) An experimental study on micro-shear clinching of metal foils by laser shock. Mater (Basel) 12(9):1422

16. Wang $X$, Ji Z, Wang $J$ et al (2018) An experimental and numerical study on laser shock clinching for joining copper foil and perforated stainless steel sheet. J Mater Process Technol 258:155-164

17. Wang $X$, Ji Z, Zheng $C$ et al (2020) Joining similar and dissimilar material combinations by laser shock forming. J Manuf Process 60:318-327

18. You S, Wang Z, Ji Z et al (2019) Making line undercut structure by incremental laser shock forming. Int J Precis Eng Manuf 20(8):1289-1296

19. Wang J, Wang Y, Wang $S$ et al (2021) Experimental and numerical investigation on incremental laser shock clinching for joining three sheets of copper/aluminum/stainless steel.Opt. Laser. Technol.141

20. Zheng C, Pan C, Wang $\mathrm{J}$ et al (2020) Mechanical joining behavior of $\mathrm{Cu}-\mathrm{Fe}$ dissimilar metallic foils in laser shock clinching. Int J Adv Manuf Technol 110(3-4):1001-1014

21. Johnson GR, Cook WH (1983) A constitutive model and data for metals subjected to large strains, high strain rates and high temperatures. 7th International Symposium on Ballistics, Hague, Netherlands, 541-547

22. Henkel AG (2014) \& Co. KGaA, Technical Data Sheet TEROSON EP 5055

\section{Figures}




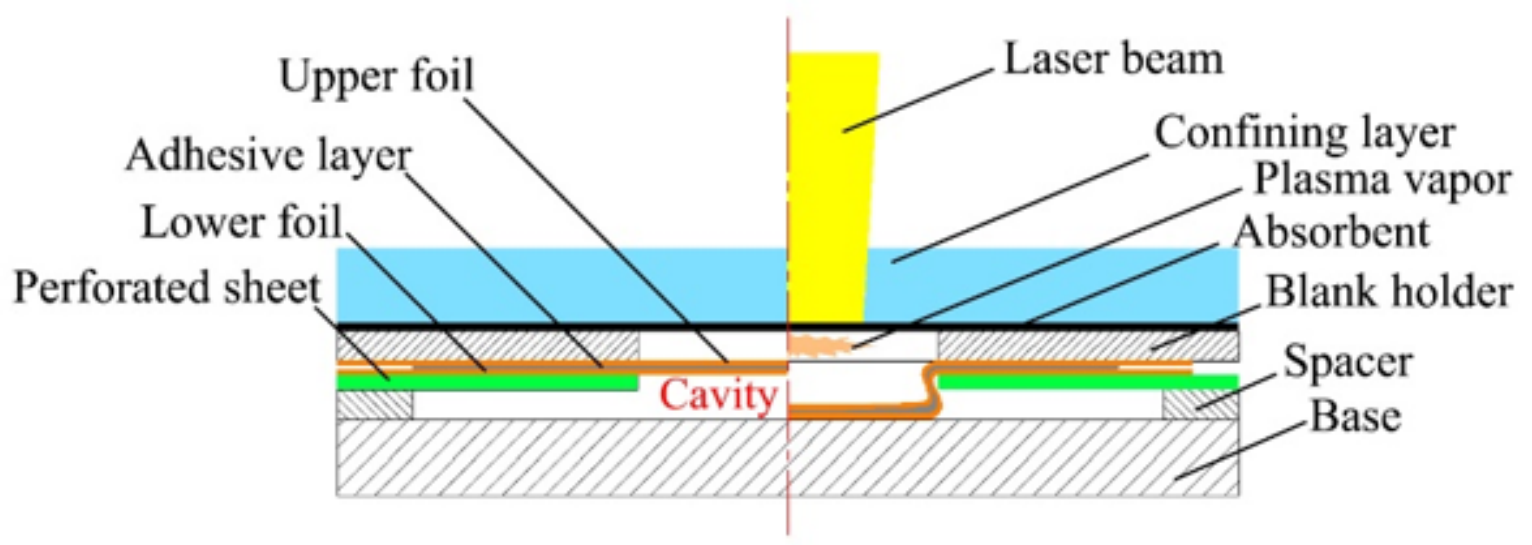

Figure 1

Schematic of one-step laser shock clinch-bonded hybrid joining.

(a)
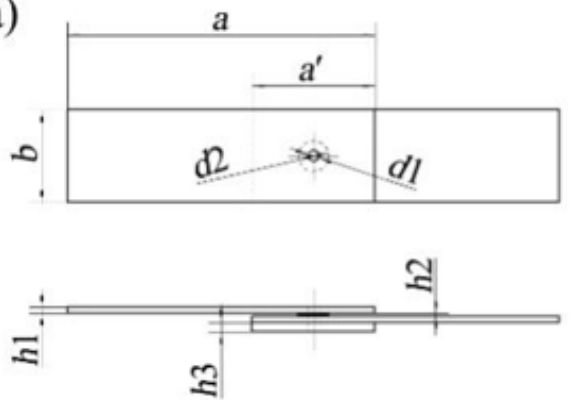

(b)
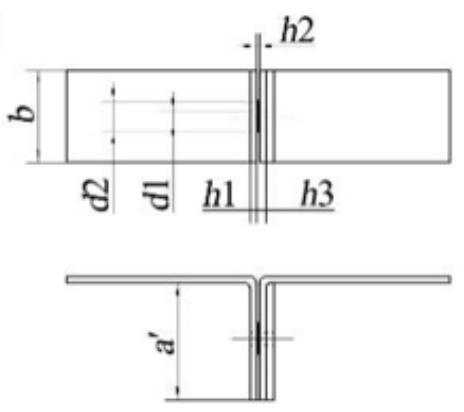

(c)

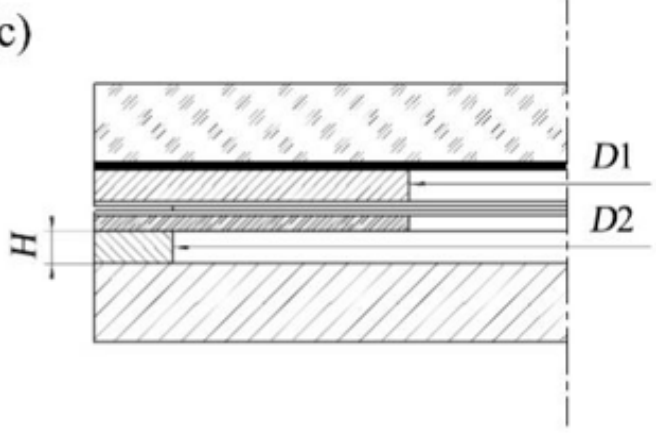

Figure 2

Schematic of (a) lap joint for the shearing test, (b) T-joint for peeling test, and (c) mold system. 


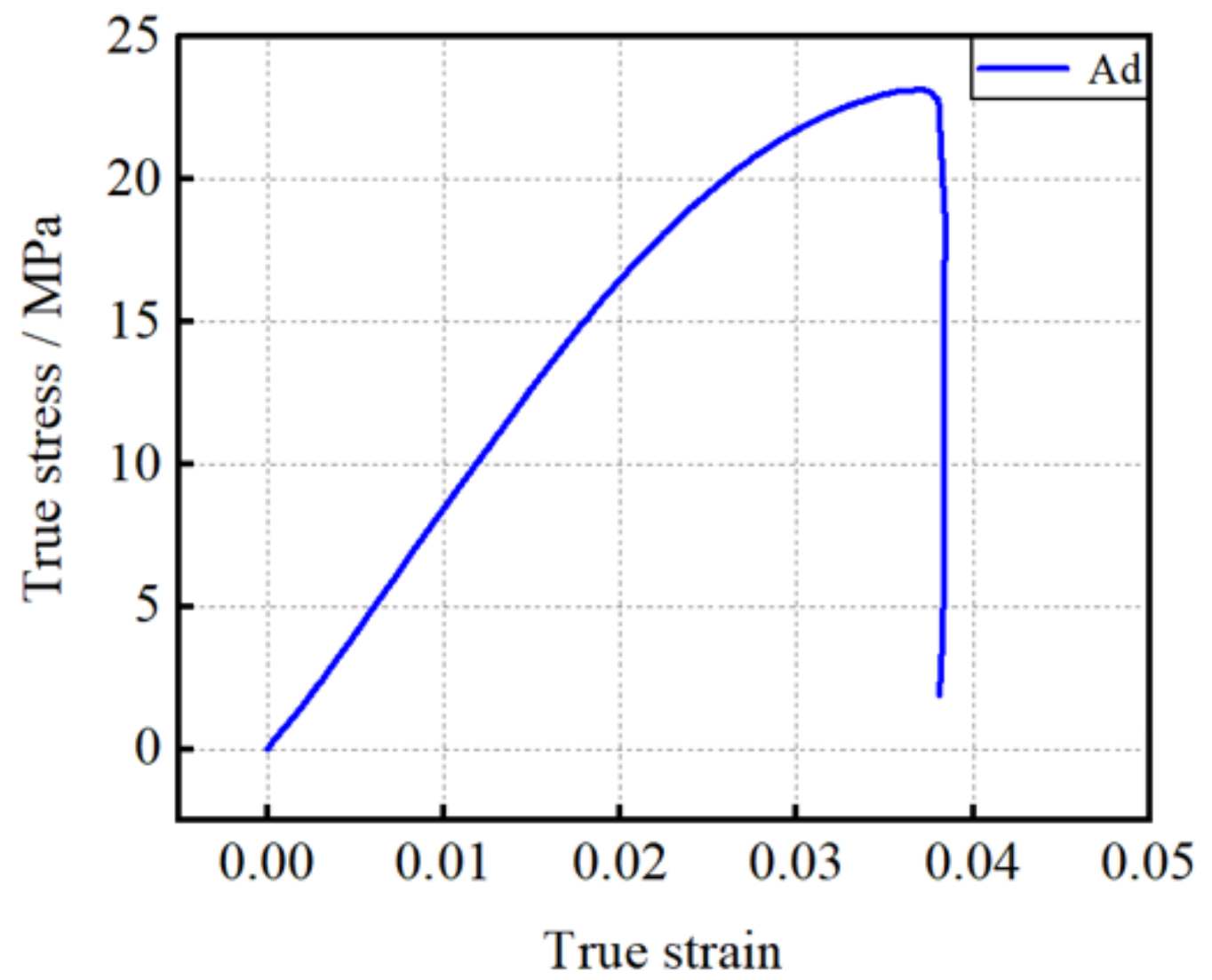

Figure 3

True stress-strain relationship of the cured adhesive. 


$\begin{array}{ll}\text { (a) Interlock } & E=320 \mathrm{~mJ} \quad \text { Interlock } \\ 36.1 \mu \mathrm{m} 27.1 \mu \mathrm{m} & \end{array}$

\section{Figure 4}

$\mathrm{Al} / \mathrm{Ad} / \mathrm{Al} / \mathrm{Ss}$ hybrid joint: (a), section view; (b), morphology; (c), adhesive feature of the area marked by the red circle in (a). 


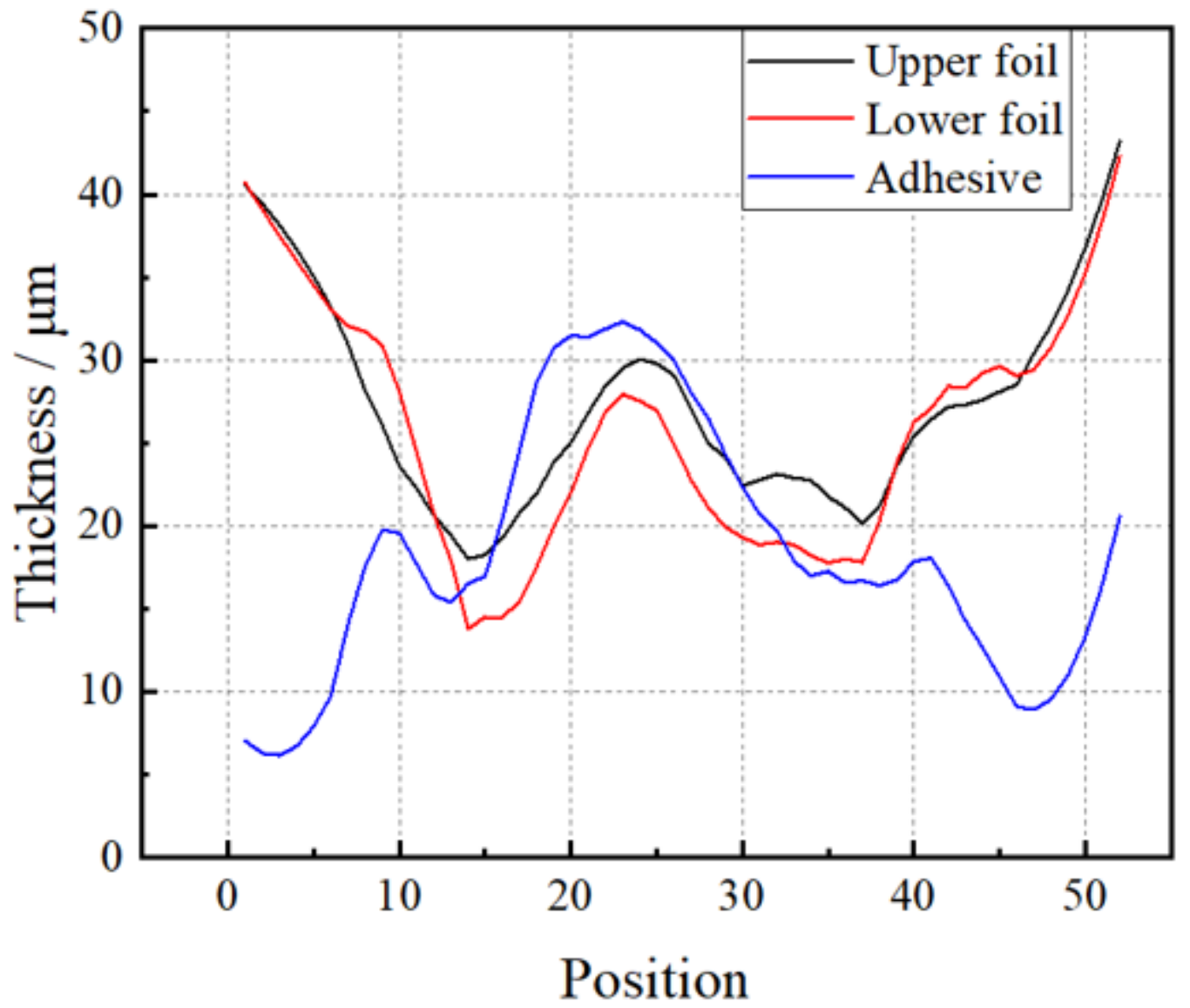

Figure 5

The thickness distribution of each layer in the hybrid joint of Fig. 5 (a), measurement positions are as signed.
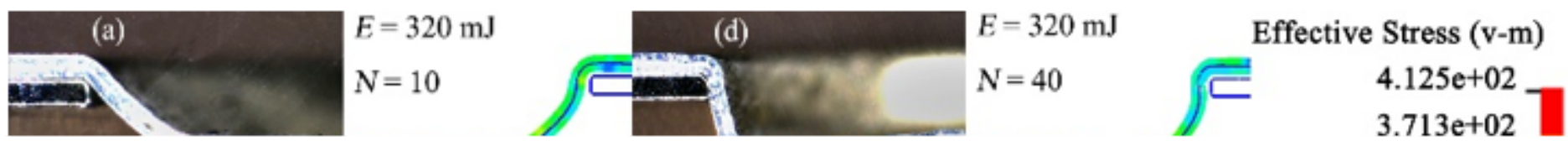

Figure 6 
Comparison between experiment and simulation results of hybrid joint section views at different forming stages during the clinching process, material deformation gradually increases as shocking number $N$ growing from (a) to (f).

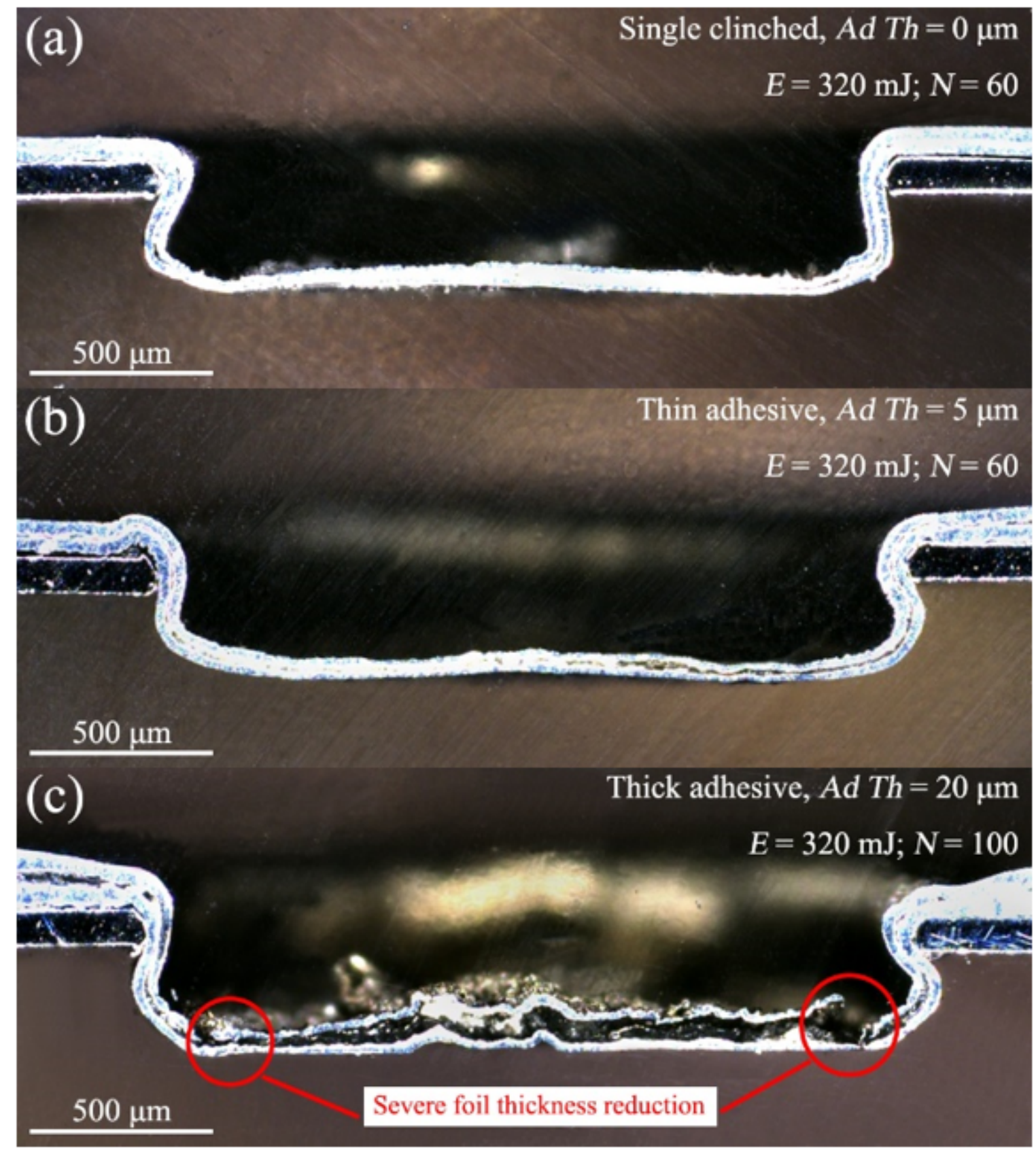

Figure 7

Section views of hybrid joints with different adhesive layer thickness: (a) $0 \mu \mathrm{m}$; (b) $5 \mu \mathrm{m}$; (c) $20 \mu \mathrm{m}$. 


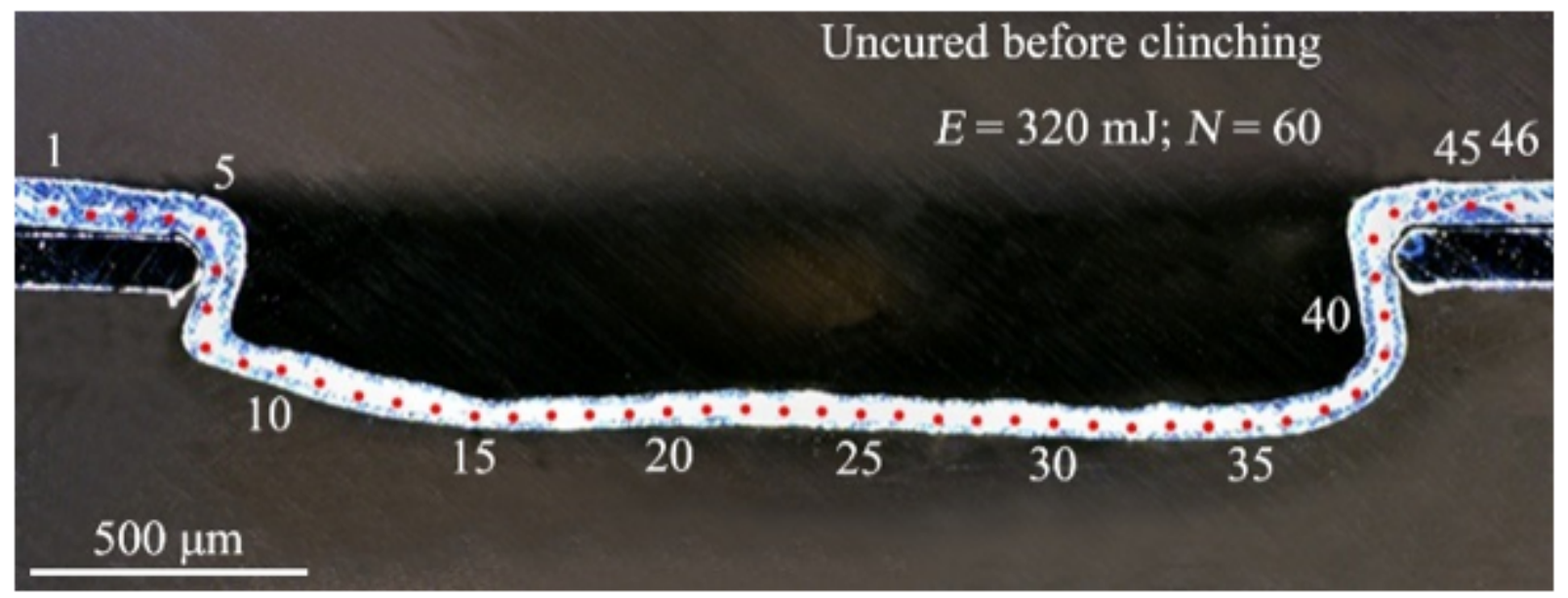

\section{Figure 8}

Section view of the hybrid joint which adhesive layer remained uncured before clinching and adhesive thickness measurement positions.

\section{Figure 9}

The thickness comparison of hybrid joints formed with uncured and cured adhesive, the measurement positions are as shown in Fig. 4 (a) and Fig. 8.

\section{Figure 10}

Shearing test results of one-step formed Al-Al joints: (a) shearing force-displacement curves; (b) maximum shearing force and energy absorption.

\section{Figure 11}

Peeling test results of two-step formed Al-Al joints: (a) peeling force-displacement curves; (b) maximum peeling force and energy absorption. 
Figure 12

Observations of failed hybrid joint: (a) inner side of upper foil; (b) inner side of lower foil; (c) failed button on upper foil; (d) failed button on lower foil.

(a)

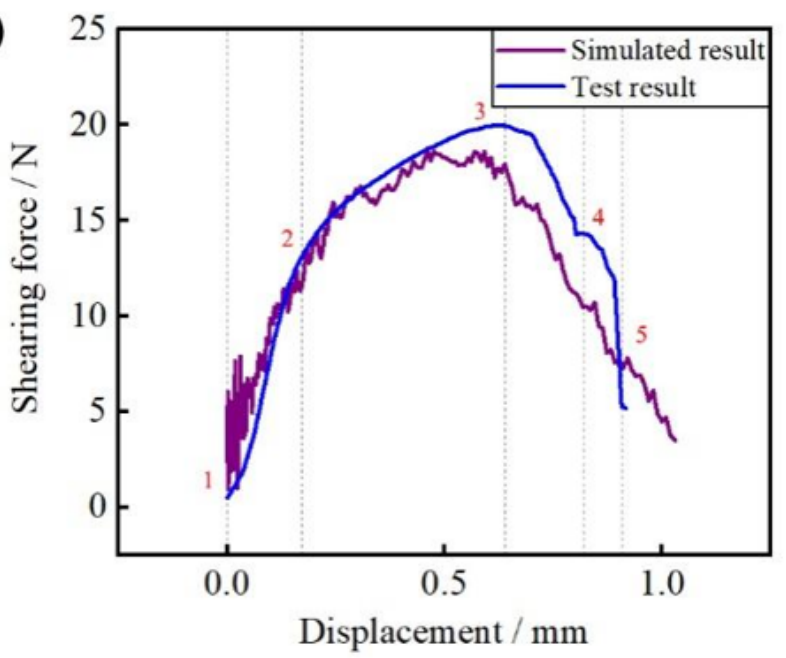

(b)

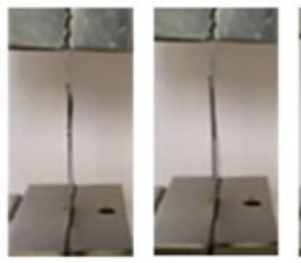

stage 1 stage 2
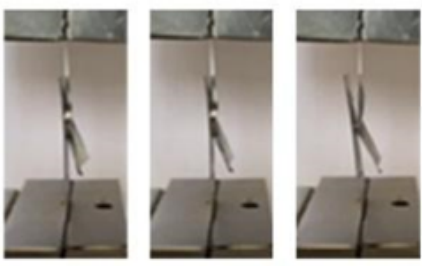

stage 3 stage 4 stage 5

Figure 13 
Pictures of the hybrid joint at different failure steps during the shearing test.
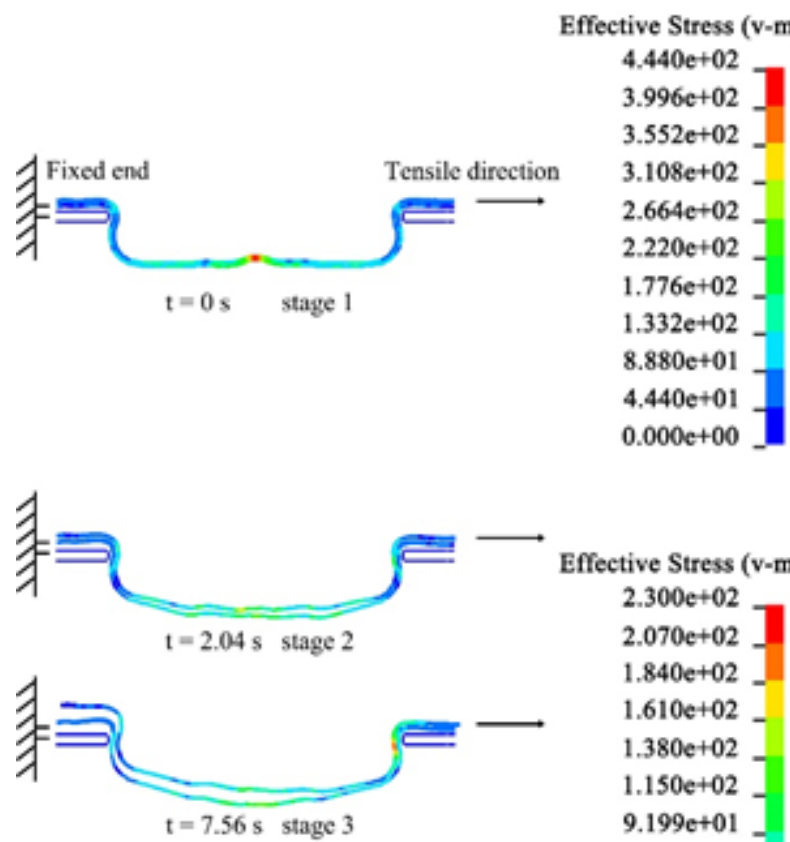

ffective Stress ( $v-m)$

$2.300 \mathrm{e}+02$

$2.070 \mathrm{e}+02$

$1.840 \mathrm{e}+02$

$1.610 \mathrm{e}+02$

$1.380 \mathrm{e}+02$

$1.150 \mathrm{e}+02$

$9.199 \mathrm{e}+01$

$6.899 \mathrm{e}+11$

$4.599 \mathrm{e}+01$

$2.300 \mathrm{e}+01$

$0.000 \mathrm{e}+00$

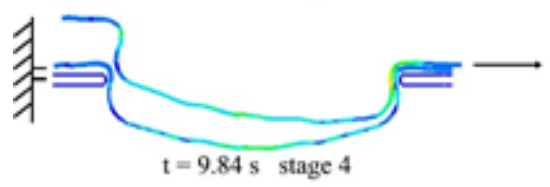

Effective Stress (v-m)

$1.709 \mathrm{e}+02$

$1.538 \mathrm{e}+02$

$1.367 \mathrm{e}+02$

$1.196 \mathrm{e}+02$

$1.025 \mathrm{e}+02$

$8.544 \mathrm{e}+01$

$6.835 \mathrm{e}+01$

$5.126 \mathrm{e}+11$

$3.418 \mathrm{e}+01$

$1.709 \mathrm{e}+01$

$0.000 \mathrm{e}+00$

Figure 14

Numerical simulation of the hybrid joint at different time in the shearing test, which corresponds to the five stages in Fig. 19. 